www.cya.unam.mx/index.php/cya

Contaduría y Administración, 64 (4), Especial Gobierno Corporativo, 2019, 1-21

\title{
El rendimiento financiero explicado a través de los principios cooperativos. Un estudio en las cooperativas de ahorro y crédito del Ecuador \\ Financial performance explained through the cooperative principles. A study in the Ecuador savings and credit cooperatives
}

\section{Edisson Coba-Molina $₫ \Xi^{1 *}{ }^{*}$, Jaime Díaz-Córdova ${ }^{1}$, Erika Tapia-Panchi ${ }^{1}$, Juan Mansilla Sepúlveda}

\author{
${ }^{1}$ Facultad de Contabilidad y Auditoría, Universidad Técnica de Ambato, Ecuador \\ ${ }^{2}$ Facultad de Educación, Universidad Católica de Temuco, Chile
}

Recibido el 6 de febrero de 2019; aceptado el 18 de septiembre de 2019

Disponible en Internet el: 18 de septiembre de 2019

\begin{abstract}
Resumen
El objetivo del artículo es analizar la influencia que tiene la aplicación de los principios cooperativos de la Alianza Cooperativa Internacional (ACI) en el rendimiento financiero de las cooperativas de ahorro y crédito de la zona centro del Ecuador en el 2017. Para ello se aplicó una encuesta a los socios de las cooperativas y la información financiera se obtuvo de la Superintendencia de Economía Popular y Solidaria. Para el análisis de datos se utilizó la técnica no paramétrica de regresión logística binaria para evaluar el impacto de los principios cooperativos como determinantes del rendimiento financiero de dichas entidades en el periodo objeto de estudio. Se evidencia que con la mayor participación económica de socios la rentabilidad mejorará. En cambio, las actividades de autogestión e independencia pueden generar altos costos asumidos por las cooperativas, disminuyendo la suficiencia patrimonial.
\end{abstract}

Código JEL: M14, P13, P31

Palabras clave: Principios cooperativos; Rendimiento financiero; Cooperativas de ahorro y crédito; Responsabilidad social

\section{Abstract}

The aim of the article is to analyze the influence that the application of the cooperative principles of the International Cooperative Alliance (ACI) has on the financial performance of the savings and credit cooperatives in the central zone of Ecuador in 2017. For this purpose, a survey of cooperative members and financial information was obtained from the Superintendency of Popular and Solidarity Economy. For data analysis, the nonparametric binary logistic regression technique was used to evaluate the impact of cooperative principles as determinants of the financial performance of said entities in the period under study. It is evident that with the greater economic participation of partners the profitability will

\footnotetext{
* Autor para correspondencia

Correo electrónicoedisoncoba@uta.edu.ec (E. Coba-Molina).

La revisión por pares es responsabilidad de la Universidad Nacional Autónoma de México.

http://dx.doi.org/10.22201/fca.24488410e.2020.2448

0186- 1042/@ 2019 Universidad Nacional Autónoma de México, Facultad de Contaduría y Administración. Este es un artículo Open Access bajo la licencia CC BY-NC-SA (https://creativecommons.org/licenses/by-nc-sa/4.0/)
} 


\section{E. Coba-Molina, et al. / Contaduría y Administración 64(4) Especial Gobierno Corporativo, 2019, 1-21 http://dx.doi.org/10.22201/fca.24488410e.2020.2448}

improve. On the other hand, the activities of self-management and independence can generate high costs assumed by the cooperatives, diminishing patrimonial sufficiency.

JEL code: $M 14, P 13, P 31$

Keywords: Cooperative principles; Financial performance; Savings and credit cooperatives; Social responsibility

\section{Introducción}

En la actualidad, el modelo de empresa tradicional denominado modelo económico está siendo sustituido por un nuevo modelo de tipo socioeconómico. Este modelo, pone de manifiesto la importancia de la Responsabilidad Social, donde las empresas crean valor para la sociedad en su conjunto, especialmente hacia sus involucrados, para convertirse en las denominadas empresas socialmente responsables, intentando de esta manera consolidar bajo esta corriente socioeconómica su posición en el mercado y generación de mayores beneficios (Nieto y Fernández, 2004).

Es así, que en el Ecuador se ha dado impulso al modelo económico denominado economía social y solidaria (ESS). Esta economía social y solidaria es una manera asociada y cooperativa de producción, distribución, circulación y consumo de bienes y servicios, sin el objetivo de lucro privado; busca resolver necesidades básicas, y mejorar la calidad de vida de todos los que en ella participan (Case y Stanescua, 2013). Es así que, las cooperativas de ahorro y crédito al ser parte del sector financiero popular y solidario tienen un factor diferenciador frente al sector de capital, que es brindar servicios financieros a segmentos de la población, cuyas necesidades de financiamiento no se satisfacen desde el sector bancario privado (Ruiz y Egüez, 2014).

En este contexto, se resaltan a los principios cooperativos como impulsores de responsabilidad social empresarial (RSE) en las cooperativas de ahorro y crédito del sector de la economía social y solidaria. El desenvolvimiento de estas organizaciones está guiado por principios cooperativos, tales como: membresía abierta y voluntaria, control democrático de los miembros, participación económica de los miembros, autogestión e independencia, educación, formación e información, cooperación entre cooperativas, compromiso con la comunidad (Chitarroni, 2013). Este tipo de organizaciones operan actividades socialmente responsables ligadas directamente con valores y principios orientados al ámbito social, económico, ambiental y cultural promoviendo el desarrollo sustentable de las comunidades en las que se insertan (Server y Capó, 2009; Belhouari Buendía, Lapointe y Tremblay, 2005; Chaves y Soler, 2004).

Sin embargo, las organizaciones como las cooperativas, cajas de ahorro, entre otras entidades, no tienen fines de lucro y su principal objetivo es la generación de beneficios sociales. La importancia de los resultados radica en analizar cómo estas organizaciones pueden ser sostenibles en el tiempo en aspectos económicos, financieros y sociales (Server y Villalonga, 2008; Agirre, 2001). La empresa cooperativa, aunque como empresa tiene que velar por su eficiencia económica para asegurarse su supervivencia, debe no obstante vigilar más la utilidad que provea a sus socios y a la sociedad en la que se inserta (Carrasco, 2005). Las cooperativas de crédito, por su propia naturaleza y por la esencia de sus principios cooperativos, se encuentran en una posición mucho más próxima a la identificación con los valores y dimensiones de la Sostenibilidad que cualquier otra entidad de crédito, y atesoran la mayor capacidad de contribución a sus objetivos económicos, medioambientales y sociales (Castro y Romero, 2011).

Por esta razón, el presente artículo pretende analizar cómo los principios cooperativos influyen en el rendimiento financiero. Para ello, se revisó la literatura sobre la importancia del cumplimiento de principios cooperativos en organizaciones sociales; y, la forma de medirlos. De igual manera se revisaron estudios previos donde se enfatiza la importancia de los resultados financieros que deben tener este tipo de organizaciones para que su sostenibilidad no se vea afectada. Con estas premisas, se relacionaron y midieron cuáles principios cooperativos son los que más impactan en el rendimiento financiero. 


\section{E. Coba-Molina, et al. / Contaduría y Administración 64(4) Especial Gobierno Corporativo, 2019, 1-21 http://dx.doi.org/10.22201/fca.24488410e.2020.2448}

\section{Marco teórico}

\section{Premisas de los principios cooperativos}

Dentro de un contexto mundial, los principios cooperativos representan el pilar fundamental dentro de la actividad operativa de las organizaciones. El sistema cooperativista ha avanzado mucho desde la declaración sobre la Identidad Cooperativa de la Alianza Cooperativa Internacional (ACI, 2008), y ahora es posible formular un marco general que defina de forma más clara la naturaleza de los valores y principios cooperativos y de sus efectos sobre la normativa cooperativa (Belhouari et. al., 2005).

La ACI (2008) menciona que los principios cooperativos expresados constituyen el denominador común ideal del movimiento cooperativo a escala mundial. La práctica de los principios cooperativos puede comprenderse como parte de las alternativas para la consecución del crecimiento empresarial y desarrollo sustentable, siempre y cuando las organizaciones manifiesten el compromiso expreso con sus involucrados (Gallego y Juliá, 2003). Además, Marcuello y Saz (2008) mencionan que los principios ponen en práctica los valores organizacionales; es decir, que los valores son el eje fundamental de los principios cooperativos como criterios para evaluar conductas y ejecutar decisiones.

Las cooperativas en todo el mundo intentan resolver una incógnita esencial: ¿cómo interactuar con la nueva realidad social, económica y tecnológica del ambiente sin amenazar los principios cooperativos y sin perjudicar la particularidad de sus objetivos? (Agirre, 2001). Sin embargo, se recalca que el desarrollo y aplicación de los principios cooperativos ayudan a generar ventajas competitivas en las cooperativas (Vargas, 2004). Las cooperativas siendo organizaciones democráticas vigiladas por sus miembros, se convierten en autores de políticas y protagonistas en la toma de decisiones, siendo al mismo tiempo responsables ante sus miembros (Huertas, 2005). La relevancia de una adecuada aplicación de los principios cooperativos por parte de sus miembros radica en asegurar la sostenibilidad de este tipo de organizaciones en el tiempo. Un rol fundamental que cumplen las cooperativas es la inclusión financiera y mayor participación de los stakeholders que les permite el desarrollo de ventajas competitivas generadoras de beneficios (Carreras y Bastida, 2015). Esto se debe a la priorización en un determinado tipo de cartera que puede considerarse como un aspecto diferenciador de estas organizaciones frente al sector de capital privado (Ruiz y Egüez, 2014).

Estudios anteriores resaltan que el cumplimiento de los principios cooperativos sirve de instrumento para lograr la supervivencia y la competitividad de la empresa cooperativa (Pedrosa y Hernández, 2011; Marcuello y Saz, 2008). Varios de ellos recalcan la importancia de evidenciar la aplicación de los principios en las cooperativas; por cuanto la finalidad de las mismas no es tanto la maximización del beneficio para los propietarios, sino ofrecerles servicios financieros de calidad (Carrasco, 2005). Las cooperativas, como el resto de las empresas deben integrar la RSE en sus estrategias en un sentido utilitarista, porque esto les proporciona ventajas competitivas, relacionadas con la reputación, la mejora de la contabilidad y la transparencia, la gestión de riesgos, o la mejora del capital humano (Carrasco, 2005).

Las cooperativas de ahorro y crédito deben evidenciar el cumplimiento de los valores y principios como una banca ética (Sanchis y Pascual, 2016). Esto con la finalidad de tener una oportunidad de afianzarse y crecer, ofertando productos y servicios financieros que cubran las necesidades de la población en riesgo de exclusión y que faciliten a la sociedad de invertir de forma socialmente responsable (Castro y Romero, 2011; Soler y Melián, 2012).

\section{Sinergia entre los principios cooperativos y los criterios de Responsabilidad Social Empresarial}

Si profundizamos y comparamos los principios cooperativos antes mencionados con los principios que propone la Comisión Europea para la promoción de la Responsabilidad Social Empresarial, se puede apreciar las semejanzas existentes entre los principios cooperativos y los de la Responsabilidad Social (Server y Capó, 2009). A continuación, se presenta la Tabla 1 
que muestra la relación entre: los principios establecidos por la Alianza Cooperativa Internacional (ACI), los Principios de la comunidad europea y la Ley Orgánica de Economía Popular y Solidaria (LOES, 2011), de este análisis surgen 7 macrodimensiones:

Tabla 1

Comparación de principios

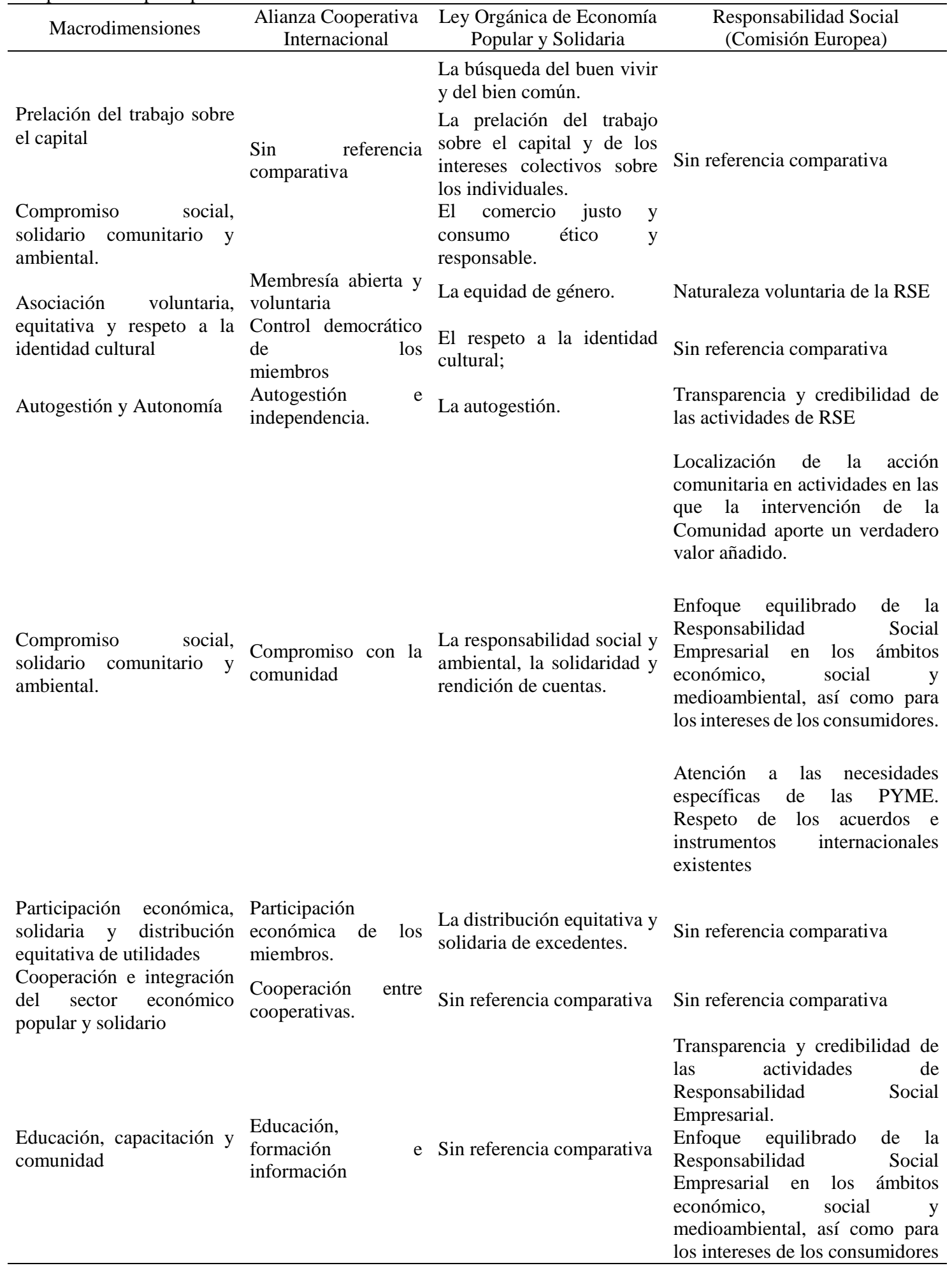




\section{E. Coba-Molina, et al. / Contaduría y Administración 64(4) Especial Gobierno Corporativo, 2019, 1-21 http://dx.doi.org/10.22201/fca.24488410e.2020.2448}

En la Tabla 1 se puede observar que algunos principios cooperativos tienen cierta similitud con los principios de la Comisión Europea. La relación de estos principios radica en la necesidad de gestión que tienen las cooperativas para desenvolverse de manera responsable y eficiente, mediante un comportamiento ético, respetando los derechos humanos, los derechos del trabajador y teniendo un equilibrio en el ámbito económico, social y ambiental (Paniagua, 2011).

Los principios cooperativos también tienen relación con los enunciados de la Organización para la Cooperación y el Desarrollo Económico (OCDE), por el propósito que persigue cada uno. El principio de capacitación, educación e información está entrelazado con fomentar la formación de capital humano, ya que las cooperativas se enfocan en ser responsables en todo lo pertinente a derechos del trabajador para lograr una gestión eficiente (Chitarroni, 2013). Otra semejanza podemos encontrar entre el principio de cooperación entre cooperativas con la directriz de alentar a los socios empresariales incluidos proveedores y subcontratistas para que apliquen principios de conducta empresarial. Finalmente, el séptimo principio cooperativo denominado interés por la comunidad se relaciona con cuatro enunciados de las directrices de la OCDE las cuales se preocupan en lograr un desarrollo sostenible, respetar los derechos humanos y estimular la generación de capacidades mediante una cooperación estrecha con la comunidad local (Chitarroni, 2013).

Aunque estos principios pueden intuir un comportamiento ético, no siempre se evidencian aquello. Bajo esta premisa Jácome y Páez (2014) exponen que no todo el desarrollo de la economía social está lleno de fortalezas; por el contrario, existen obstáculos que ponen a prueba sus postulados. Por ejemplo, en el caso de las cooperativas de ahorro y crédito las limitaciones en los montos que ofrecen no permiten satisfacer la demanda, con lo cual los interesados deben recurrir a la banca privada, generando un muy bajo impacto en la solución de los problemas de la comunidad (Castro y Romero, 2011).

\section{Rendimiento financiero en las cooperativas de ahorro y crédito}

Las cooperativas son sociedades de marcado carácter social cuyo objetivo es facilitar a sus socios determinados bienes o servicios al mejor precio o retribuir sus prestaciones al máximo posible (Carmona, Martínez y Ponzuelo; 2012). En el Ecuador la Ley Orgánica de la Economía Popular y Solidaria (2011), les exige a las Cooperativas de Ahorro y Crédito, incorporar en sus informes de gestión el cumplimiento de los principios cooperativos para acreditar sus objetivos sociales.

Este tipo de organizaciones se rigen por una serie de principios o características que las hacen diferentes de las sociedades mercantiles o capitalistas (el capital variable y su remuneración, el reparto del resultado en función de las operaciones realizadas por cada socio y la asignación obligatoria de parte de este resultado a la educación, formación y promoción de sus socios y trabajadores). El rendimiento financiero en este tipo de organizaciones es la retribución de la inversión realizada por los socios en el uso de los recursos generadores de excedentes. Dichos resultados pueden ser analizados a priori o posteriori y dan fe del desempeño de la economía social en un país (Gratenol, Alizo, y Molero, 2010).

En este sentido, dentro del entorno empresarial, es esencial evaluar el desempeño económico y financiero, de tal manera que se pueda apreciar el desenvolvimiento de la entidad en cuanto a liquidez, solvencia, endeudamiento y rentabilidad con el fin de facilitar la toma de decisiones (Correa, Castaño y Ramirez, 2010). Además, la aplicación de los principios cooperativos, generan una ventaja competitiva que permite un mejor rendimiento financiero en el largo plazo, siendo necesario que las acciones llevadas a cabo provengan de una visión estratégica (Vélez, 2010).

Por otro lado, resulta necesario identificar cuáles son las medidas de rendimiento que se utilizan para medir el resultado financiero en las cooperativas. En el estudio realizado en Colombia-Antioquía se evalúo el rendimiento financiero de las cooperativas a través de indicadores financieros como la liquidez, solvencia y endeudamiento. Estos indicadores se

seleccionaron por considerarse como elementales ya que les permite tomar decisiones adecuadas, que contribuyan al crecimiento y por ende al beneficio de sus socios (Castaño, Gallego, Quintero y Vergara, 2016). De igual forma los 
indicadores utilizados en varios estudios cooperativos para evaluar el rendimiento financiero han sido: la liquidez, solvencia, endeudamiento, rentabilidad y la capacidad de generar excedentes (Graterol, Alizo y Molero, 2010; Krause y Konzen; 2002).

Por su parte en la investigación realizada a las cooperativas españolas (Carmona, Martínez y Pozuelo, 2012), se utilizaron indicadores para analizar evolución económica de las mismas como: rentabilidad financiera, rentabilidad económica, solvencia, actividad, endeudamiento, y presión fiscal. Este estudio muestra que la rentabilidad y las demás ratios analizados han ido empeorando como consecuencia de los efectos de la crisis económica que atravesó España. En cambio, Da Silva, Leite, Guse y Gollo (2017) utilizaron el modelo CAMEL al analizar a las cooperativas más grandes de Brasil. Sus resultados muestran que cuanto mayor sean las tasas del desempeño económico y financiero del CAMEL, mayor será el desempeño dirigido a la capacidad de crecimiento de la actividad crediticia para los clientes asociados. También confirman que en Brasil las cooperativas tienen una posición más conservadora, ya que prefieren no arriesgar el capital de sus miembros asociados. De igual forma Díaz, Coba, Hidalgo y Valencia (2017) utilizando el mismo modelo CAMEL para analizar a una de las cooperativas más grandes del Ecuador, se observa que la Suficiencia Patrimonial y el índice de Morosidad fueron unos de los indicadores que mejores resultados presentó. Mientras que el rendimiento de la cartera tuvo un bajo nivel confirmando que la entidad tendría la capacidad mínima de generar utilidades o ganancias para los socios en el periodo económico.

También en la literatura se evidencian estudios donde el rendimiento de las cooperativas se mide por su nivel de endeudamiento y liquidez. Es así que, en la investigación realizada en el estado de Zulia, se determinó que un alto porcentaje de las cooperativas si pueden cubrir sus obligaciones financieras y los excedentes de los socios. A su vez, un alto porcentaje de las cooperativas generan un excedente en operación capaz de cubrir los intereses y el resto de las obligaciones fijas a pagar (Graterol, Alizo y Molero, 2010). También Krause y Konzen (2002) afirman que la liquidez general en las cooperativas brasileñas estudiadas fue positiva. Y muestran evidencias que apuntan a un mejor desarrollo cuando las cooperativas registran remanentes al final del ejercicio, de los cuales la mayor parte tendrán como destino el asignado por la Asamblea General.

En cambio, Lara y Pérez (2015) utilizaron indicadores financieros como: activos totales, cartera total, la captación total y el índice de morosidad para establecer si las sociedades cooperativas de ahorro y préstamo se hacen isomorfas a la banca formal en México. Estos autores manifiestan la existencia de algunas similitudes entre las cooperativas y la banca, como el caso de los índices de cartera total y captaciones. En cuanto al índice de morosidad, la similitud es leve ya que depende del nivel de formalización en las entidades financieras que pueden tener un impacto positivo en la reducción de la morosidad de sus clientes.

Sin embargo, como lo afirman Belhouari et. al. (2005) en el caso de las cooperativas, sus principios, su estructura y su dinámica específica han sido limitaciones constantes de cara a su evaluación empresarial al aplicarse los mismos indicadores que al resto de organizaciones empresariales. Por lo que resulta necesario considerar otros factores tales como su finalidad y la satisfacción de los socios, la democracia como criterio en los procesos de toma de decisión y la justicia en el reparto de los excedentes desde la perspectiva de los todos aquellos beneficios que las cooperativas transfieren a sus grupos de influencia. Por lo que, las cooperativas deben tener un comportamiento ético, a la par de una gestión eficiente, es lo que asegura una estabilidad a largo plazo (Carrasco, 2005)

Dada la variedad de indicadores utilizados para medir el rendimiento en las cooperativas de intermediación financiera, cuya finalidad última es el fin social; hemos seleccionado para la presente investigación los indicadores financieros de rentabilidad total, rentabilidad sobre la cartera, índice de morosidad, suficiencia patrimonial y liquidez, que son las de mayor interés en instituciones de intermediación financiera. Cabe recalcar que el impacto de una adecuada gestión del modelo cooperativo, se puede medir en términos de rentabilidad tanto financiera como social. Sin embargo, en este tipo 


\section{E. Coba-Molina, et al. / Contaduría y Administración 64(4) Especial Gobierno Corporativo, 2019, 1-21 \\ http://dx.doi.org/10.22201/fca.24488410e.2020.2448}

de organizaciones va de la mano la aplicación de sólidos principios cooperativos para que las entidades puedan ser sostenibles en el tiempo, teniendo implícitamente un razonable rendimiento financiero y al mismo tiempo mejoren la calidad de vida de sus socios. En términos de economía social, podemos decir que la adecuada aplicación de los principios cooperativos serán los principales precursores de desarrollo en condiciones de sostenibilidad, integración y bienestar social (Zubiaurre, Andicoechea, \& Saitua, 2016).

\section{Metodología}

El desarrollo de este apartado se divide en dos secciones. En primer lugar, se realizó una encuesta a los socios de las cooperativas de ahorro y crédito del segmento 1 de la zona 3 del Ecuador, que a diciembre del 2017 lo conformaban cinco cooperativas dentro de este segmento. A cada una de ellas se solicitó por escrito la autorización a la gerencia para aplicar una encuesta a sus socios, de las cuales 4 de ellas autorizaron su aplicación. Con la finalidad de obtener una muestra representativa de cada cooperativa dado el número de sucursales que tiene cada una de ellas en el centro del país, se aplicaron 30 encuestas en cada una de las 25 agencias de las 4 cooperativas (total 750 encuestas). El índice de respuesta obtenido fue del $75 \%$ que equivalen a 563 encuestas válidas.

En segundo lugar, se obtuvo información financiera a partir de la Superintendencia de Economía Popular y Solidaria (SEPS) correspondiente al año 2017. De esta manera se pretende identificar cuáles son los principios cooperativos que aporten o inciden en el desempeño financiero medido por: rentabilidad, índice de morosidad, rendimiento de cartera, suficiencia patrimonial y liquidez.

La encuesta estuvo conformada por 6 apartados de preguntas relacionadas al nivel de cumplimiento de los principios cooperativos que recomienda la ACI. Las preguntas utilizaron una escala de Likert (1 "No está de acuerdo" a 5 "Muy de acuerdo"). En la Tabla 2, se detallan el número de ítems utilizados en cada dimensión (principio) y la descripción general de las preguntas.

Tabla 2

Cuadro resumen de dimensiones y de ítems del estudio

\begin{tabular}{|c|c|c|c|}
\hline Variables Independientes & $\begin{array}{l}\text { Variables } \\
\text { Código }\end{array}$ & Número de Ítems & Variables Descripción \\
\hline $\begin{array}{l}\text { Membresía abierta y } \\
\text { voluntaria }\end{array}$ & MV & 10 & $\begin{array}{l}\text { Elecciones democráticas de representantes, } \\
\text { inclusión de mujeres, sector indígena, atención } \\
\text { del personal }\end{array}$ \\
\hline $\begin{array}{l}\text { Control democrático de } \\
\text { los miembros }\end{array}$ & DM & 3 & Gestión democrática, ética, justicia honestidad. \\
\hline $\begin{array}{l}\text { Participación económica } \\
\text { de los miembros }\end{array}$ & $\mathrm{PE}$ & 15 & $\begin{array}{l}\text { Satisfacción de los socios, beneficios de los } \\
\text { créditos, adecuadas tasas de interés, calidad vida } \\
\text { laboral. }\end{array}$ \\
\hline $\begin{array}{l}\text { Autogestión } \\
\text { independencia }\end{array}$ & AI & 11 & $\begin{array}{l}\text { Calidad de servicios de banca virtual, call center, } \\
\text { salud, comunicación, eficiencia, prestigio }\end{array}$ \\
\hline $\begin{array}{l}\text { Compromiso con la } \\
\text { comunidad }\end{array}$ & $\mathrm{CC}$ & 18 & $\begin{array}{l}\text { Cumplimiento de promesas, leyes, aporte a la } \\
\text { comunidad, medio ambiente, programas a niños, } \\
\text { discapacitados, ancianos, mujeres embarazadas. }\end{array}$ \\
\hline $\begin{array}{l}\text { Cooperación } \\
\text { cooperativas }\end{array}$ & Cco & 2 & Comercio justo, transparencia \\
\hline Variables Dependientes & $\begin{array}{l}\text { Variables } \\
\text { Código }\end{array}$ & Valoración & Variables Descripción \\
\hline Rentabilidad & Rentab & $\begin{array}{l}\text { Resultados de } \\
\text { Ejercicio/Patrimo } \\
\text { nio Promedio }\end{array}$ & $\begin{array}{l}\text { Mide el nivel de retorno generado por el } \\
\text { patrimonio invertido por los socios de la entidad } \\
\text { financiera }\end{array}$ \\
\hline Índice de morosidad & IndMor & $\begin{array}{l}\text { Cartera } \\
\text { Improductiva/Cart } \\
\text { era Bruta }\end{array}$ & $\begin{array}{l}\text { Mide el porcentaje de la cartera improductiva } \\
\text { frente al total cartera (proporción de la cartera } \\
\text { que se encuentra en mora). Las ratios de }\end{array}$ \\
\hline
\end{tabular}




\begin{tabular}{|c|c|c|c|}
\hline Rendimiento Cartera & RenCar & $\begin{array}{l}\text { Interés de la } \\
\text { cartera/Promedio } \\
\text { de la cartera por } \\
\text { vencer }\end{array}$ & $\begin{array}{l}\text { morosidad se calculan para el total de la cartera } \\
\text { bruta. } \\
\text { Se refiere al rendimiento que tiene la cartera de } \\
\text { cada tipo de créditos, sujeto a una banda } \\
\text { maduración, } \\
\text { es decir, en función del rango del vencimiento } \\
\text { futuro de las operaciones }\end{array}$ \\
\hline Suficiencia Patrimonial & SufPatr & $\begin{array}{l}\text { (Patrimonio } \\
\text { Resultados) } \\
\text { Activos } \\
\text { Inmovilizados }\end{array}$ & $\begin{array}{l}\text { Se refiere a la relación porcentual de cobertura } \\
\text { que tiene una entidad financiera de los posibles } \\
\text { riesgos ponderados de sus partidas de activo }\end{array}$ \\
\hline Liquidez & Liq & $\begin{array}{l}\text { Fondos } \\
\text { Disponibles/Depó } \\
\text { sitos a Corto Plazo }\end{array}$ & $\begin{array}{l}\text { Refleja la Liquidez que posee cada entidad, con } \\
\text { el uso de dos cuentas fundamentales que son la } \\
\text { cantidad de fondos disponibles sobre los } \\
\text { depósitos a corto plazo. En la cual se mide la } \\
\text { capacidad de responder a obligaciones } \\
\text { inmediatas }\end{array}$ \\
\hline
\end{tabular}

Fuente: Elaboración propia y SEPS (2017)

En la Tabla 3 se recoge el índice de homogeneidad corregido (IHc - correlación entre el elemento y el total de la escala sin el elemento) y el valor del Alfa de Cronbach para el total de la escala si se prescinde del elemento. Tal y como se puede observar, en general la fiabilidad individual de cada uno de los ítems es significativa, dado que superan, en la mayoría de los casos, el valor de 0.50. Se destacan los ítems de la dimensión cooperación entre cooperativas (0,936 con 2 items), control democrático de sus miembros (0,88 con 3 ítems), seguidos de los ítems de la dimensión compromiso con la comunidad (0,87 con 18 ítems). Por otra parte, las puntuaciones más bajas corresponden a los ítems de la dimensión membresía abierta y voluntaria (0,65 con 10 ítems) que parecerían ser menos consistentes con el resto de las escalas, aunque su eliminación no parece conllevar un aumento importante en la consistencia global del instrumento que tiene un valor de 0,972 .

Tabla 3

Descriptivos para los elementos que componen la escala abreviada

$\begin{array}{ll}\text { Items } & \begin{array}{l}\text { Correlación } \\ \text { elemento-total } \\ \text { corregida }\end{array}\end{array} \begin{aligned} & \text { Alfa de Cronbach si se } \\ & \text { elimina el elemento }\end{aligned}$

PE Participación Económica de sus Miembros

PE1 Es responsablemente social por el trato de los empleados $\quad$,417 $\quad, 787$

PE2 Es responsablemente social por la satisfacción de los socios $\quad, 367 \quad, 790$

PE3 La responsabilidad social es el mejoramiento de los créditos $\quad, 199 \quad, 799$

PE4 La responsabilidad social es la disminución de las tasas de interés ,207 ,799

$\begin{array}{lllll}\text { PE5 La responsabilidad social es la calidad en la vida laboral } & , 274 & , 795\end{array}$

PE6 Que beneficio le brindo el crédito de consumo $\quad, 490 \quad, 779$

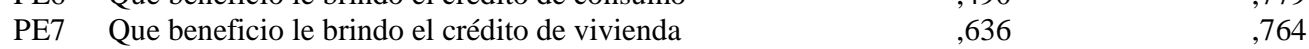

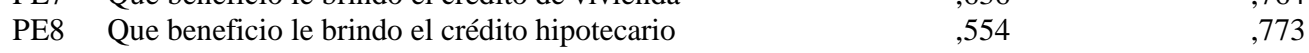

PE9 Que beneficio le brindo el crédito vehicular $\quad, 521 \quad, 776$

PE10 Que beneficio le brindo el crédito para microempresas $\quad$,430 ,785

$\begin{array}{lll}\text { PE11 Que beneficio le brindo el crédito educativo } & , 606 & , 767\end{array}$

PE12 Debe enfocarse en los trabajadores $\quad, 157 \quad, 801$

PE13 Debe enfocarse en los socios $\quad, 160 \quad, 801$

PE14 La relación entre los créditos que ha requerido y el interés pagado , ,459 $\begin{array}{lll}\text { PE15 Usted considera que los intereses pagados por la cooperativa en } & , 489 & , 781 \\ \text { relación a sus depósitos a la vista y depósitos a plazo son } & , 489\end{array}$ 


\begin{tabular}{|c|c|c|c|}
\hline \multicolumn{4}{|c|}{ AI Autogestión e independencia } \\
\hline AI1 & Tiene servicio médico & ,389 & ,711 \\
\hline AI2 & Tiene servicio odontológico & ,397 & ,710 \\
\hline AI3 & Tiene servicio de call center & ,290 & ,720 \\
\hline AI4 & Tiene servicio de banca virtual & ,233 & ,726 \\
\hline AI5 & Tiene servicio de auto banca &, 127 & ,735 \\
\hline AI6 & Es responsablemente social por el buen servicio &, 516 & ,686 \\
\hline AI7 & Es responsablemente social por los medios de comunicación &, 545 & ,680 \\
\hline AI8 & Es responsablemente social por el prestigio &, 584 & ,672 \\
\hline AI9 & Es responsablemente social por la eficiencia &, 569 & ,675 \\
\hline AI10 & $\begin{array}{l}\text { ¿Está de acuerdo con que las cooperativas que practican } \\
\text { responsabilidad social lo den a conocer a través de campañas } \\
\text { masivas de publicidad? }\end{array}$ &, 119 &, 734 \\
\hline AI11 & La imagen de la cooperativa que usted es socio le parece & ,267 & ,731 \\
\hline Alfa de & e Cronbach Total & & ,798 \\
\hline \multicolumn{4}{|c|}{ CC Compromiso con la comunidad } \\
\hline $\mathrm{CC} 1$ & Es responsablemente social por el aporte a la comunidad &, 512 & ,863 \\
\hline $\mathrm{CC} 2$ & Es responsablemente social porque cumple lo que promete &, 588 & ,859 \\
\hline $\mathrm{CC} 3$ & Es responsablemente social porque cumple con las leyes & 648 & ,858 \\
\hline $\mathrm{CC} 4$ & Es responsablemente social porque no daña al medio ambiente &, 593 &, 859 \\
\hline CC5 & La gente no se da cuenta & ,494 & ,864 \\
\hline CC6 & Que importancia tiene la ayuda mutua &, 553 & ,861 \\
\hline $\mathrm{CC} 7$ & Que importancia tiene el esfuerzo propio & ,437 & ,865 \\
\hline $\mathrm{CC} 8$ & Que importancia tiene el respeto social & ,475 & ,864 \\
\hline CC9 & La responsabilidad social es la ayuda a la comunidad & ,438 & ,865 \\
\hline $\mathrm{CC} 10$ & $\begin{array}{l}\text { La responsabilidad social es hacerse cargo de los problemas de la } \\
\text { sociedad }\end{array}$ & ,432 & ,866 \\
\hline $\mathrm{CC} 11$ & $\begin{array}{l}\text { La responsabilidad social es cuidar el medio ambiente y el entorno } \\
\text { donde se desarrolla }\end{array}$ & ,459 &, 865 \\
\hline $\mathrm{CC} 12$ & Debe enfocarse en la comunidad & ,440 & ,865 \\
\hline $\mathrm{CC} 13$ & Debe enfocarse con las personas con discapacidad &, 503 & ,863 \\
\hline $\mathrm{CC} 14$ & Debe enfocarse con las personas de la tercera edad &, 531 & ,862 \\
\hline $\mathrm{CC} 15$ & Debe enfocarse en los niños &, 401 &, 867 \\
\hline $\mathrm{CC} 16$ & Debe enfocarse en el medio ambiente & ,448 & ,865 \\
\hline $\mathrm{CC} 17$ & Le brinda un buen servicio a los ancianos & ,432 & ,866 \\
\hline $\mathrm{CC} 18$ & Le brinda un buen servicio a las mujeres embarazadas & ,422 & ,866 \\
\hline Alfa de & e Cronbach Total & &, 870 \\
\hline \multicolumn{4}{|c|}{ DM Control democrático de sus miembros } \\
\hline DM1 & Que importancia tiene la justicia y la honestidad & ,771 & ,828 \\
\hline DM2 & Que importancia tiene la gestión democrática & 753 & ,846 \\
\hline DM3 & Que importancia tiene la ética & ,782 & ,818 \\
\hline Alfa de & e Cronbach Total & &, 880 \\
\hline \multicolumn{4}{|c|}{ Cco Cooperación entre cooperativas } \\
\hline Cco1 & Que importancia tiene el comercio justo & ,759 & ,939 \\
\hline $\mathrm{Cco} 2$ & Que importancia tiene la transparencia & ,759 & ,937 \\
\hline Alfa de & e Cronbach Total & & ,936 \\
\hline \multicolumn{4}{|c|}{ MV Membresía abierta y voluntaria } \\
\hline MV1 & Le brinda un buen servicio a las personas indígenas & ,220 & ,676 \\
\hline MV2 & Le brinda un buen servicio a las mujeres con niños en brazos & ,378 & ,614 \\
\hline MV3 & Es importante la disposición del personal al momento del crédito &, 561 & ,569 \\
\hline MV4 & Es importante el trato del personal al momento del crédito &, 564 &, 576 \\
\hline MV5 & $\begin{array}{l}\text { Usted seria socio de otra cooperativa, solo porque esta realice } \\
\text { prácticas sociales. }\end{array}$ & ,096 & ,659 \\
\hline MV6 & $\begin{array}{l}\text { Su cooperativa ha realizado votaciones democráticas para la } \\
\text { elección de representantes }\end{array}$ &, 080 & ,661 \\
\hline MV7 & $\begin{array}{l}\text { Cree usted que puede influir como socio la manera como la } \\
\text { cooperativa es socialmente responsable. }\end{array}$ &,- 030 & ,669 \\
\hline
\end{tabular}


MV8 ¿Ha considerado en retirar su dinero de la cooperativa por NO ser socialmente responsable?

, 159

, 545

, 507

MV10 Es importante la rapidez del personal al momento del crédito

Alfa de Cronbach Total

Alfa de Cronbach Total de ítems

Fuente: Elaboración propia

Con el objetivo de estudiar la validez de cada constructo de la escala se realizó el cálculo la fiabilidad de los 6 constructos con el índice de fiabilidad compuesta (IFC) utilizando el software PLS, que se interpreta como el alfa de Cronbach pero tiene en cuenta las interrelaciones de los constructos extraídos. La fiabilidad compuesta fue desarrollada por Werts, Linn y Jöreskog (1974) y se calcula así:

$$
I F C=\frac{[\operatorname{SUMA}(a i j)]^{2}}{[S U M A(a i j)]^{2}+S U M A \operatorname{Var}(E i j)}
$$

Donde:

$a i j=$ carga factorial estandarizada de cada uno de los $\mathrm{i}$ indicadores que cargan sobre el factor $\mathrm{j}$

$\operatorname{Var}(E i j)=$ varianza del término de error asociado a cada uno de los i indicadores del factor $\mathrm{j}$. Teniendo en cuenta que este error (Eij) también se puede calcular como: $1-a i j^{\wedge} 2$

Como indica la Tabla 4, la fiabilidad compuesta para cada constructo es mayor que 0.70. Ello implica que cada conjunto de ítems explica una parte de la variación del concepto con la medida del error.

Tabla 4

Índice de Fiabilidad Compuesta

Variables

Fiabilidad compuesta

\begin{tabular}{ll}
\hline Autogestión Independencia & 0.757 \\
Compromiso Comunidad & 0.892 \\
Control Democrático & 0.926 \\
Cooperación Cooperativas & 0.936 \\
Membresía Abierta Voluntaria & 0.739 \\
Participación Económica & 0.824 \\
\hline
\end{tabular}

, 651

, 651

,972 
Tabla 5

Estadísticos descriptivos de las variables

\begin{tabular}{llllll}
\hline Estadísticos & Media & Mediana & Desv. típ. & Mínimo & Máximo \\
\hline Membresía abierta y voluntaria (MV) & 3,69 & 4,00 & 1,04 & 1,00 & 5,00 \\
Control democrático de sus miembros (DM) & 2,99 & 3,00 & 1,27 & 1,00 & 5,00 \\
Participación Económica de los miembros (PE) & 2,91 & 3,00 & 0,95 & 1,00 & 5,00 \\
Autogestión e Independencia (AI) & 3,22 & 3,00 & 0,98 & 1,00 & 5,00 \\
Compromiso con la Comunidad (CC) & 3,40 & 3,00 & 1,00 & 2,00 & 5,00 \\
Cooperación de Cooperativas (Cco) & 2,87 & 3,00 & 1,18 & 1,00 & 5,00 \\
Suficiencia Patrimonial (SufPatr) & 17,64 & 11,83 & 13,38 & 1,52 & 33,06 \\
Rentabilidad (Rentab) & 0,11 & 0,11 & 0,03 & 0,05 & 0,15 \\
Indices de morosidad (IndMor) & 0,06 & 0,07 & 0,01 & 0,04 & 0,07 \\
Rendimiento de la Cartera (RenCar) & 0,18 & 0,19 & 0,01 & 0,16 & 0,19 \\
Liquidez (Liq) & 0,89 & 0,44 & 1,24 & 0,25 & 3,82 \\
\hline
\end{tabular}

Fuente: Elaboración propia

Como observamos en la Tabla 5, el promedio de la rentabilidad (Rentab) anual de las cooperativas es de $11 \%$ y la desviación estándar es de 0,03. Asimismo, el máximo y mínimo fueron de 5\% a 15\%. En general las cooperativas de la muestra presentan una buena rentabilidad y oportunidades de crecimiento, ya que la variable (RenCar) presenta una media (mediana) de 18\% (19\%) y una desviación estándar de (0,01). Respecto al índice de morosidad (IndMor), el promedio es de $6 \%$ y la desviación estándar de 0,01 , de la misma forma el mínimo y máximo van de $4 \%$ a 7\%, lo cual evidencia un mejor control de la cartera lo que permite a las cooperativas tener un aceptable crecimiento de los créditos en la zona centro del Ecuador y mejorar los resultados para sus socios.

Con la finalidad de tener una mejor aproximación del aporte en el accionar de las cooperativas a través del cumplimiento de sus principios, se presenta a continuación los siguientes análisis que permitan ser más concluyentes en el impacto financiero.

\section{Discusión y Resultados}

\section{Estimación del modelo y su valoración}

Con la finalidad de evitar los inconvenientes de los supuestos previos que requieren los modelos de regresión lineal o análisis discriminante (Mures, García y Vallejo, 2005), se aplicó la regresión logística binaria como técnica para plantear un modelo cuya variable respuesta o dependiente es una variable dummy con un valor cero (0) cuando el rendimiento, la suficiencia patrimonial, la morosidad, el rendimiento de la cartera, y la liquidez, son bajos, y uno (1) cuando son altos. La variable dummy se creó a partir del promedio de cada variable como punto de corte. Aquellos valores inferiores al punto de corte toman el valor de 0 y los superiores el valor de 1.

El modelo de regresión logística puede formularse como:

$$
\log \left(\frac{p}{1-p}\right)=\beta_{0}+\beta_{1} x_{1}+\beta_{2} x_{2}+\beta_{3} x_{3}+\cdots+\beta_{k} x_{k}
$$


donde $\mathrm{p}$ es la probabilidad de ocurrencia del evento de interés, en este caso, niveles altos en los indicadores financieros. Dado el valor de las variables independientes, la probabilidad señalada puede ser calculada directamente de la siguiente forma (Wiginton 1980):

$$
p=\frac{e^{z}}{1+e^{z}}=\frac{1}{1+e^{-z}}
$$

$$
\text { Siendo } Z=\beta_{0}+\beta_{1} x_{1}+\beta_{2} x_{2}+\beta_{3} x_{3}+\cdots+\beta_{k} x_{k}
$$

Para alcanzar el objetivo del estudio se realizaron 5 modelos causales que representan un modelo general para las 4 cooperativas de estudio, utilizando el módulo de regresión logística binaria del software SPSS versión 21. Cada modelo se lo realizó sobre los determinantes del desempeño financiero: suficiencia patrimonial, rentabilidad, índices de morosidad, rendimiento de cartera, y liquidez. De esta forma la probabilidad de bajo desempeño financiero p (expresión 4), está explicado por cada uno de principios cooperativos.

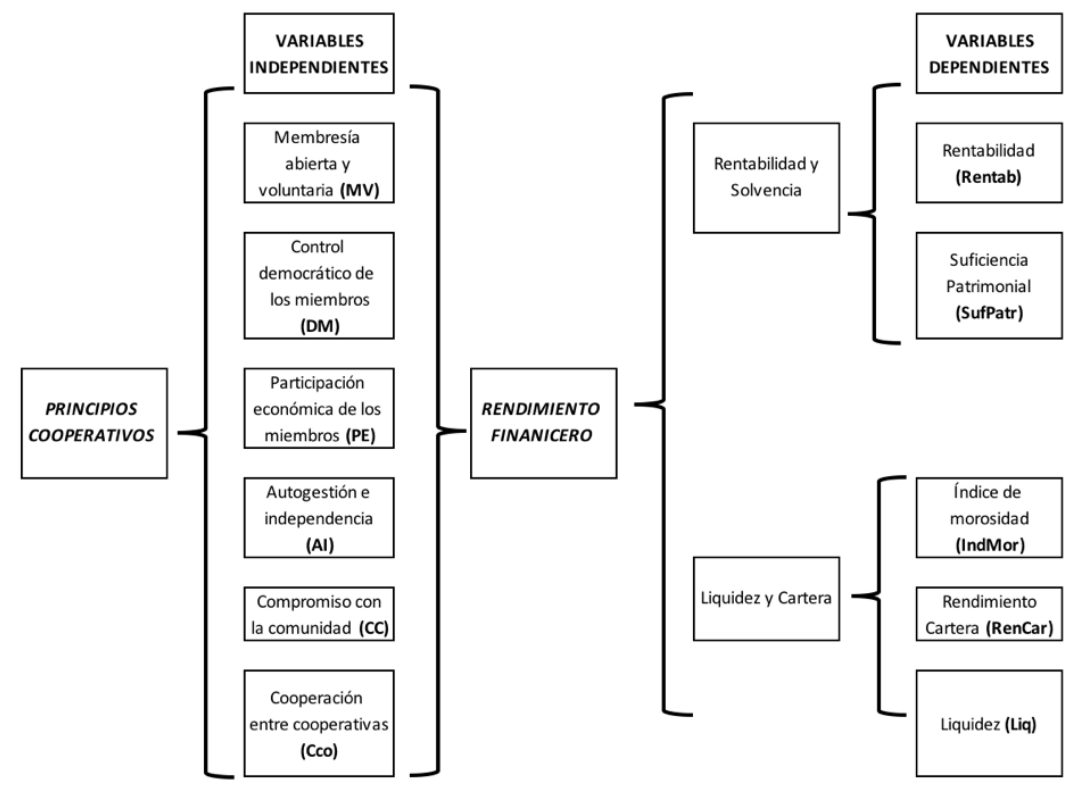

Figura 1. Modelo explicativo propuesto de los principios cooperativos y su efecto en el rendimiento financiero

Fuente: Elaboración propia

\section{Análisis de los resultados}

A continuación, se presentan los resultados de las estimaciones relativas al estudio de la causalidad entre la aplicación de los principios cooperativos y las variables dependientes de las cooperativas de ahorro y crédito. En la Tabla 6 se presenta los resultados obtenidos: 
E. Coba-Molina, et al. / Contaduría y Administración 64(4) Especial Gobierno Corporativo, 2019, 1-21 http://dx.doi.org/10.22201/fca.24488410e.2020.2448

Tabla 6

Variables de la ecuación

\begin{tabular}{lllllll}
\hline \multicolumn{5}{c}{ Variable } & \multicolumn{3}{c}{ Dependiente: } & \multicolumn{2}{l}{$\begin{array}{l}\text { Variable } \\
\text { Rentabilidad }\end{array}$} & Dependiente: \\
Variables & \multicolumn{1}{c}{ Suficiencia Patrimonial } & & & \\
& B & Sig. & Wald & B & Sig. & Wald \\
\hline Constante & 1,245 & $0,002 *$ & 9,925 & 0,445 & 0,246 & 1,344 \\
PE & 0,355 & $0,002 *$ & 9,184 & 0,426 & $0,000 *$ & 13,596 \\
AI & $-0,338$ & $0,004 *$ & 8,449 & $-0,175$ & 0,127 & 2,331 \\
CC & 0,036 & 0,774 & 0,083 & 0,044 & 0,724 & 0,125 \\
DM & 0,047 & 0,672 & 0,235 & 0,163 & 0,091 & 2,848 \\
Cco & $-0,305$ & $0,003 *$ & 8,991 & $-0,324$ & $0,001 *$ & 10,470 \\
MV & $-0,259$ & $0,012 *$ & 6,370 & $-0,109$ & 0,283 & 1,151 \\
$\begin{array}{l}\text { Sig. Modelo } \\
\text { Porcentaje } \\
\text { clasificación }\end{array}$ & & $0.000 *$ & & & $0,000 *$ & \\
\hline
\end{tabular}

\begin{tabular}{|c|c|c|c|c|c|c|c|c|c|}
\hline 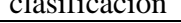 & & \\
\hline \multirow{2}{*}{ Variables } & \multicolumn{3}{|c|}{$\begin{array}{l}\text { Variable Dependiente: } \\
\text { Rendimiento de la Cartera }\end{array}$} & \multicolumn{3}{|c|}{$\begin{array}{l}\text { Variable Dependiente: Índices } \\
\text { de morosidad }\end{array}$} & \multicolumn{2}{|c|}{$\begin{array}{l}\text { Variable } \\
\text { Liquidez }\end{array}$} & Dependiente: \\
\hline & $\mathrm{B}$ & Sig. & Wald & B & Sig. & Wald & B & Sig. & Wald \\
\hline Constante & 2,261 & $0,000 *$ & 20,314 & 2,716 & $0.000 *$ & 40,209 & $-4,043$ & $0,000^{*}$ & 53,114 \\
\hline PE & 0,526 & $0,000 *$ & 13,910 & 0,295 & $0,012^{*}$ & 13,668 & 0,111 & 0,409 & 0,683 \\
\hline AI & $-0,370$ & $0,008 *$ & 7,012 & $-0,438$ & $0,000 *$ & 13,668 & 0,253 & 0,076 & ,3158 \\
\hline $\mathrm{CC}$ & 0,124 & 0,404 & 0,696 & 0,082 & 0,517 & 0,420 & 0,009 & 0,954 & 0,003 \\
\hline $\mathrm{DM}$ & $-0,264$ & $0,020 *$ & 5,401 & $-0,305$ & $0,002 *$ & 9,912 & 0,165 & 0,152 & 2,051 \\
\hline Cco & $-0,219$ & 0,064 & 3,432 & $-0,122$ & 0,222 & 1,491 & $-0,048$ & 0,692 & 0,157 \\
\hline MV & $-0,029$ & 0,821 & 0,051 & $-0,185$ & 0,082 & 3,018 & 0,257 & 0,054 & 3,714 \\
\hline Sig. Modelo & & 0.000 & & & 0,000 & & & 0,000 & \\
\hline $\begin{array}{l}\text { Porcentaje } \\
\text { clasificación }\end{array}$ & de & 79,9 & & & 61,1 & & & 81,2 & \\
\hline
\end{tabular}

**. La relación es significativa al nivel 0,01 (bilateral).

*. La relación es significante al nivel 0,05 (bilateral).

Fuente: Elaboración propia

En primer lugar, se procedió a verificar la hipótesis para saber si todos los coeficientes de cada modelo son significativos en términos estadísticos. Como se observa en la tabla 6 , solo algunas variables de los principios cooperativos resultaron ser estadísticamente significativas a un nivel de significancia del $5 \%(\alpha=0,05)$ para ciertas variables dependientes consideradas como rendimiento financiero. Por ello, se seleccionó el método Introducir para esta regresión logística que ha permitido decidir qué variables se introducen o extraen del modelo, para mejorar el análisis en función de los resultados que se iban obteniendo. La selección de este método permite especificar cómo se introducen las variables independientes en el análisis.

Una vez que se ha ajustado cada uno de los modelos escogiendo las variables independientes más influyentes, se procedió a evaluar dicho ajuste. Para obtener la bondad del ajuste de los modelos de regresión logística se aplica la prueba denominada Hosmer-Lemeshow (Hosmer y Lemeshow, 2004). Para que el ajuste sea bueno, a diferencia de otras pruebas, lo que se desea en esta prueba es que no haya significación, y en nuestro caso se cumple en todas las regresiones, a excepción 
E. Coba-Molina, et al. / Contaduría y Administración 64(4) Especial Gobierno Corporativo, 2019, 1-21

http://dx.doi.org/10.22201/fca.24488410e.2020.2448

del modelo de liquidez. Por lo tanto, en adelante no se continuará evaluando la regresión con la variable dependiente liquidez debido a la baja confiabilidad de predicción.

Tabla 7

Prueba de Hosmer y Lemeshow

\begin{tabular}{lll}
\hline Modelos con cada variable dependiente & Chi cuadrado & Sig. \\
\hline Suficiencia patrimonial & 9,925 & 0,270 \\
Rentabilidad & 13,044 & 0,071 \\
Rendimiento de la cartera & 10,178 & 0,253 \\
Indice de Morosidad & 5,154 & 0,641 \\
Liquidez & 29,299 & 0,000 \\
\hline
\end{tabular}

Fuente: Elaboración propia

Estos resultados muestran que las probabilidades pronosticadas no se desvían de las probabilidades observadas, es decir que la regresión binaria predice y se ajusta el modelo a los datos de forma aceptable.

En el presente estudio el valor que se obtuvo en el R2 de Nagelkerke para la suficiencia patrimonial fue de 9,4\%; es decir que solo el 9.4\% de la proporción de varianza de la variable dependiente Suficiencia Patrimonial es explicada por la variable explicativa principios cooperativos y el modelo clasifica correctamente al $62.3 \%$ de los casos. La rentabilidad por su parte obtuvo en el R2 de Nagelkerke de 4,6\% y el modelo clasifica correctamente al 59.9\% de los casos. El rendimiento de la cartera obtuvo en el R2 de Nagelkerke fue de 8,8\% y clasifica correctamente al 80.5\% de los casos. Por último, el índice de morosidad el valor que se obtuvo en el R2 de Nagelkerke de 13,6\% y clasifica correctamente al $68.2 \%$ de los casos.

La prueba ómnibus que evalúa la hipótesis nula de que los coeficientes $\beta 1$ de todas las variables (excepto la constante) incluidas en el modelo sean cero. La significación estadística obtenida en el Chi Cuadrado fue de p<0,000 en todos los modelos, lo que nos indica que los modelos con las variables introducidas mejora el ajuste de forma significativa.

Por último, se presentan en las siguientes tablas las variables de la ecuación, los coeficientes de regresión con sus correspondientes errores estándar (ET), el valor del estadístico de Wald para evaluar la hipótesis nula, la significación estadística asociada y el valor de la OR.

Tabla 8

Modelo de regresión con variables más influyentes en la suficiencia patrimonial

\begin{tabular}{llllll}
\hline $\begin{array}{l}\text { Variables } \\
\text { Introducidas }\end{array}$ & B & E.T. & Wald & Sig. & Exp(B) \\
\hline PE & 0,369 & 0,115 & 10,360 & $0,001 * *$ & 1,447 \\
AI & $-0,322$ & 0,112 & 8,294 & $0,004 * *$ & 0,725 \\
Cco & $-0,272$ & 0,087 & 9,692 & $0,002 * *$ & 0,762 \\
MV & $-0,244$ & 0,099 & 6,115 & $0,013 *$ & 0,784 \\
Constante & 1,262 & 0,387 & 10,629 & $0,001 * *$ & 3,534 \\
\hline
\end{tabular}

**. La relación es significativa al nivel 0,01 (bilateral).

*. La relación es significante al nivel 0,05 (bilateral).

Fuente: Elaboración propia 
Tabla 9

Modelo de regresión con variables más influyentes en la Rentabilidad

\begin{tabular}{llllll} 
Variables Introducidas & B & E.T. & Wald & Sig. & Exp(B) \\
\hline PE & 0,377 & 0,102 & 13,728 & $0,000^{* *}$ & 1,457 \\
Cco & $-0,273$ & 0,081 & 11,458 & $0,001 * *$ & 0,761 \\
Constante & 0,116 & 0,308 & 0,141 & 0,708 & 1,122 \\
\hline
\end{tabular}

**. La relación es significativa al nivel 0,01 (bilateral).

*. La relación es significante al nivel 0,05 (bilateral).

Fuente: Elaboración propia

En el presente estudio se encontraron los siguientes resultados: en el primer modelo, la suficiencia patrimonial tiene una relación inversa con los coeficientes que acompañan a las variables AI, Cco y MV. Esto quiere decir, que las cooperativas cuando incrementan su autogestión ofreciendo servicios sin costo a sus socios como banca en línea, servicios médicos, mejor trato y servicio al socio, mayor democracia, transparencia y competencia justa entre cooperativas provoca un incremento de sus gastos operativos dando un impacto negativo en la suficiencia patrimonial. Esto es consecuente con lo mencionado por Castro y Romero (2011) quienes afirman que muchas cooperativas de crédito siguen mostrando una pesada y rígida estructura de costos, basada en la cercanía al cliente, lo que les exige disponer, en términos relativos, de una extensa red de oficinas y de una amplia plantilla. Y en el caso de las cooperativas de mayor tamaño como las del presente estudio requieren más sacrificio de recursos para su adecuada operación sobre todo el cubrir el bienestar de sus agremiados que son también en gran número, siendo sus gastos operativos altos (Castaño, Gallego, Quintero y Vergara, 2016). Por lo que resulta necesario, gestionar el balance cooperativo para compensar posibles caídas en la solvencia y rentabilidad, por ejemplo, desinvirtiendo en activos poco rentables o mejorando la cantidad y la calidad de los servicios prestados. Por otro lado, el principio de participación económica (PE) de sus miembros refleja un impacto positivo en la suficiencia patrimonial. Esto demuestra que las cooperativas al brindar sus servicios crediticios y de inversiones conforme a las necesidades de sus socios genera confianza en las operaciones financieras de la cooperativa, generando buenos resultados patrimoniales.

En cambio, la rentabilidad de las cooperativas se incrementará si se da énfasis al principio cooperativo de participación económica de sus miembros (PE); y se verá afectada cuando la cooperación entre cooperativas (Cco) aumente sus vínculos externos generando costos operativos. La participación económica incluye adecuado trato, satisfacción en los procesos de crédito, intereses razonables, y productos financieros acorde a las necesidades de sus miembros. Si bien las cooperativas actúan en el mercado en las mismas condiciones que la banca privada, su orientación de negocio y el destino de los excedentes son una muestra de la preocupación social de estas entidades (Chávez y Soler; 2005). De esta forma se motiva a una mejor participación económica permitiendo que la cooperativa tenga resultados que permitan ser sostenibles y cubrir las expectativas para los cuales fue creada. Por su parte, Iturrioz y Dopacio (2009) manifiestan que en las sociedades cooperativas el rendimiento obtenido se reparte a los socios (retorno cooperativo) no en función del capital social aportado, sino de la participación de cada uno en la obtención del citado resultado. Este sistema hace que el socio que más participa (más compra, más vende o mas trabaja, según el caso) tenga una retribución superior. Es así que, los principios cooperativos y su dinámica de funcionamiento pudiera ser un elemento clave en la obtención de una mayor rentabilidad de estas entidades con relación a los bancos comerciales (Belhouari et. al., 2005). Es por ello, que las cooperativas suelen participar en una mayor divulgación de la aplicación de sus principios cooperativos para aumentar la confianza pública y atraer a más miembros y por ende mejorar su rentabilidad (Mathuva; 2016). En cambio, la cooperación entre cooperativas y otras formas solidarias, puede afectar la rentabilidad al considerar los costos operativos que surgen por la necesidad de desarrollar actividades, alianzas y negocios que permitan el ofrecimiento de mejores servicios o el acceso a mejores precios para los 


\section{E. Coba-Molina, et al. / Contaduría y Administración 64(4) Especial Gobierno Corporativo, 2019, 1-21 http://dx.doi.org/10.22201/fca.24488410e.2020.2448}

asociados. Como lo menciona Martínez (2012) por un lado, se fortalece los vínculos interinstitucionales, sacrificando el resultado financiero individual, por la cooperación de unas con otras hacia un fin común. Las ventajas de la cooperación se proyectan más en el largo plazo como el conseguir una mayor representación gremial y presión política, obtener financiación, compartir dificultades, y, en suma, competir mejor, no entre ellas mismas, sino con sus competidores en los mercados.

Tabla 10

Modelo de regresión con variables más influyentes en la Rendimiento de Cartera

\begin{tabular}{llllll}
\hline $\begin{array}{l}\text { Variables } \\
\text { Introducidas }\end{array}$ & B & E.T. & Wald & Sig. & Exp(B) \\
\hline PE & 0,518 & 0,136 & 14,504 & $0,000^{* *}$ & 1,679 \\
AI & $-0,379$ & 0,130 & 8,512 & $0.004^{* *}$ & 0,685 \\
DM & $-0,335$ & 0,096 & 12,107 & $0,001^{* *}$ & 0,715 \\
Constante & 2,196 & 0,440 & 24,929 & $0,000^{* *}$ & 8,991 \\
\hline
\end{tabular}

**. La relación es significativa al nivel 0,01 (bilateral).

*. La relación es significante al nivel 0,05 (bilateral).

Fuente: Elaboración propia

Tabla 11

Modelo de regresión con variables más influyentes en la Morosidad

\begin{tabular}{llllll}
$\begin{array}{l}\text { Variables } \\
\text { Introducidas }\end{array}$ & B & E.T. & Wald & Sig. & Exp(B) \\
\hline PE & 0,249 & 0,112 & 4,950 & $0,026^{* *}$ & 1,283 \\
AI & $-0,480$ & 0,110 & 18,915 & $0,000^{* *}$ & 0,619 \\
DM & $-0,363$ & 0,082 & 19,696 & $0,000^{* *}$ & 0,696 \\
Constante & 2,401 & 0,371 & 41,970 & $0,000^{* *}$ & 11,031 \\
\hline
\end{tabular}

**. La relación es significativa al nivel 0,01 (bilateral).

*. La relación es significante al nivel 0,05 (bilateral).

Fuente: Elaboración propia

El rendimiento de la cartera por su parte, tiene un coeficiente positivo PE; y dos coeficientes negativos AI y DM. $\mathrm{Al}$ igual que la suficiencia patrimonial el PE y el AI afectan de forma significativa en los resultados de las cooperativas. Se debe considerar que la gestión de créditos representa el compromiso de las cooperativas con los intereses de los asociados y también coincide con la susceptibilidad al principio cooperativo de compartir el riesgo y la responsabilidad mutua (Da Silva et. al., 2017). Este resultado es congruente con lo mostrado por Díaz et. al. (2017) donde el rendimiento de la cartera en las cooperativas es bajo, debido a que tienden a dar más prioridad al monto de créditos y no a la rentabilidad de los mismos. Esto se debe a que las cooperativas suelen dar financiamiento a sus socios a tipos de interés preferenciales que son inferiores en el mercado financiero; incluso con excesiva concentración del riesgo, pues suelen depender de un único segmento de clientes (Castro y Romero, 2011).

El índice de morosidad tiene una relación inversa con los principios AI y DM. Aquellas cooperativas que mejoran su autogestión e independencia, muestran una mayor participación de sus miembros en la gestión democrática y sus actividades reflejan valores de justicia y honestidad; el impacto será un índice de morosidad menor. Sin embargo, a mayor independencia y autogestión el rendimiento financiero tendrá un impacto negativo debido al incremento de gastos operativos en la gestión y servicio social que brindan a sus socios. Sin embargo, las cooperativas se están viendo presionadas para incorporar entre sus criterios de gestión, el análisis y control del riesgo de crédito. Y a través de la mejora de sus servicios, 


\section{E. Coba-Molina, et al. / Contaduría y Administración 64(4) Especial Gobierno Corporativo, 2019, 1-21 http://dx.doi.org/10.22201/fca.24488410e.2020.2448}

su imagen y reputación se verá salvaguardada, permitiendo una mejor gestión del riesgo de sostenibilidad, especialmente vinculado a la actividad crediticia (Castro y Romero, 2011).

\section{Conclusiones}

El presente estudio resalta la importancia de la aplicación de los principios cooperativos en las instituciones financieras del sector social y solidario del Ecuador, permitiéndoles obtener un beneficio colectivo, y al mismo tiempo resultados financieros adecuados. Se destaca también a la ACI, como modelo de organización a nivel internacional, que se centra en la promoción y defensa de la identidad cooperativa. Uno de los principales aportes de la ACI ha sido la Declaración de Identidad Cooperativa con la formulación de los Principios y Valores. Así, la aplicación y profundización de los propios Principios Cooperativos supondría avanzar en la RSE de las cooperativas.

Un reto de las cooperativas de ahorro y crédito es el ser sostenibles en el tiempo. Es decir, que estas organizaciones cubran las necesidades sociales de sus socios mediante la oferta productos y servicios financieros socialmente responsables, y a su vez tenga la capacidad de generar rendimientos económicos razonables para la reinversión en la propia institución y sus asociados. Es ahí donde, el presente estudio analiza la relación de los principios cooperativos y su efecto en el rendimiento financiero de estas organizaciones.

En tal sentido, entre los principales resultados tenemos que el principio que aporta a una mejora en la rentabilidad total es la prevalencia de una mayor participación económica de sus miembros en la cooperativa. Esto se da a través de satisfacción en los procesos de crédito, intereses razonables y productos financieros que cubran las necesidades de sus socios.

La rentabilidad de la cartera como tal se ve beneficiada también por la participación económica de sus miembros y compromiso con la comunidad. Sin embargo, a mayor autogestión e independencia de la cooperativa, el rendimiento de la cartera puede disminuir. La suficiencia patrimonial al igual que el rendimiento de la cartera puede verse afectada por la autogestión e independencia, ya que este último principio puede generar una estructura de costos cooperativos pesada, por tratar de brindar gran cantidad de servicios financieros que requieren personal y apertura de distintas sucursales que muchas veces originan costos que asumen las cooperativas.

El índice de morosidad por su parte tiende a disminuir si la autogestión, independencia y control democrático de sus miembros incrementa. Esto denota un mayor compromiso de sus socios al cumplir con la obligación de sus créditos, cuando la cooperativa brinda servicios financieros adecuados y prevalezcan los valores de justicia, honestidad, ética y democracia en cada accionar cooperativo.

Los resultados obtenidos son congruentes con lo esperado en el trabajo ya que el actuar de las cooperativas se fundamenta en principios y valores del cooperativismo, por lo que su objetivo está enmarcado en la generación de valor económico y social en favor de sus grupos de interés. Esto quiere decir, que realizan actividades económicas rentables, a fin de obtener rendimientos que se destinarán al beneficio de los socios y la comunidad.

De forma general, los indicadores financieros del segmento 1 de la zona centro del Ecuador, se muestra como un sector estable enmarcado en los principios cooperativos. En los últimos años se ha venido fortaleciendo patrimonialmente con resultados positivos y generando beneficio social para sus asociados. Dicha contribución se refleja, tanto en el aumento del crédito, justamente por ser un modelo alternativo que suple necesidades de recursos en condiciones favorables para los asociados, como en los bajos índices de morosidad y los índices de rentabilidad obtenida.

El presente trabajo abre nuevas posibilidades de investigación en la que puede incluirse un mayor número de cooperativas, considerando los diferentes segmentos clasificados por tamaño en activos y número de socios. Adicionalmente, sería relevante estudiar y comparar el comportamiento de las cooperativas con la banca privada que también realizan actividades de responsabilidad social, buscando establecer, si las cooperativas de ahorro y crédito muestran 
mayor nivel de cumplimiento en principios y valores, ubicándose en el dilema de la interacción entre su identidad institucional o la búsqueda de un mejor rendimiento financiero que la banca.

\section{Referencias}

Alianza Cooperativa Internacional - ACI. (2008). Estatuto Alianza Cooperativa Internacional. Disponible en: http://www.aciamericas.coop/IMG/pdf/aci_estatutos.pdf

Agirre, A. (2001). Los principios cooperativos "atractores" de la gestión eficiente: su medición. Aplicación al caso de Mondragón Corporación Cooperativa. CIRIEC-España, Revista de Economía Pública, Social y Cooperativa, (39), 93-113. Disponible en: http://www.redalyc.org/pdf/174/17403906.pdf

Belhouari, A., Buendía, I., Lapointe, M., y Tremblay, B. (2005). La responsabilidad social de las empresas: ¿un nuevo valor para las cooperativas? CIRIEC-España. Revista de Economía Pública, Social y Cooperativa, (53), 191-208. Disponible en: http://www.redalyc.org/pdf/174/17405313.pdf

Case S., y Stanescua S. (2013). Role of the social economy to increase social inclusion., Procedia - Social and Behavioral Sciences, 92, 117-121. Disponible en: https://www.sciencedirect.com/science/article/pii/S1877042813027778

Carmona, P., Martínez, J., y Pozuelo, J. (2013). Diagnóstico económico-financiero de la empresa cooperativa. Un estudio comparado de los años 2004 y 2007. REVESCO Revista de Estudios Cooperativos, (110), 43-95. Disponible en: https://doi.org/10.5209/rev_REVE.2013.v110.41444

Carrasco, I. (2005). La ética como eficiencia: la responsabilidad social en las cooperativas de crédito españolas. CIRIECEspaña, Revista de Economía Publica, Social y Cooperativa, (53), 351-367. Disponible en: http://www.redalyc.org/articulo.oa?id=17405320

Carreras, L., y Bastida, R. (2015). Estudio sobre la rendición de cuentas en materia de responsabilidad social: el balance social. CIRIEC- España, Revista de Economía Publica, Social y Cooperativa, (84), 251-277. Disponible en: http://www.redalyc.org/pdf/174/17442313009.pdf

Castaño, C., Gallego, D., Quintero, D., \& Vergara, K. (2016). Evaluación del desempeño de las cooperativas de ahorro y crédito de antioquia para el periodo 2009-2013. Performance evaluation of credit unions of antioch for the period. Revista Science of Human Action, 1 (2), 175-210. Retrieved from http://www.funlam.edu.co/revistas/index.php/SHA/article/view/2154/1660

Castro, M., y Romero, N. (2011). Cooperativas de crédito y banca ética ¿un camino por explorar? CIRIEC-España, Revista de Economía Pública, Social y Cooperativa, (72), 263-300. Disponible en: http://www.redalyc.org/pdf/174/17421345010.pdf

Chitarroni, A. (2013). Responsabilidad Social Empresaria: ¿Una traslación de los principios cooperativos al ámbito de las empresas comerciales? $\quad$ Enfoques, 25(1), 39-64. Disponible en: http://www.scielo.org.ar/pdf/enfoques/v25n1/v25n1a04.pdf

Da Silva T., Leite M., Guse J., y Gollo V. (2017). Desempeño financiero y económico de las principales cooperativas de crédito brasileñas. Contaduría y Administración 62. 1442-1459. Disponible en: https://doi.org/10.1016/j.cya.2017.05.006 


\section{E. Coba-Molina, et al. / Contaduría y Administración 64(4) Especial Gobierno Corporativo, 2019, 1-21 http://dx.doi.org/10.22201/fca.24488410e.2020.2448}

Díaz J., Coba E., Hidalgo C., Valencia E., y Bonilla J. (2017). Conjuntos borrosos aplicado al sector cooperativo del Ecuador. Política y Cultura. Vol. 47. 227-253. Disponible en: http://www.scielo.org.mx/pdf/polcul/n47/01887742-polcul-47-00227.pdf

Gallego, L., y Juliá, J. (2003). Principios cooperativos y eficacia económica. Un análisis Delphi en el contexto normativo español. CIRIEC-España, Revista de Economía Pública, Social y Cooperativa, (44), 231-259. Disponible en: http://www.redalyc.org/articulo.oa?id=17404408

Graterol, Á., Alizo, M., y Molero, N. (2010). Evaluación del rendimiento financiero a las cooperativas del municipio Maracaibo, Edo . Zulia . Periodo: 1999-2006. Omnia, (2), 150-177. Disponible en: http://www.produccioncientifica.luz.edu.ve/index.php/omnia/article/viewFile/7322/7310

Hosmer, D. W., \& Lemeshow, S. (2004). Applied logistic regression. Textbook and solutions manual (2nd ed.). New York, USA: John Wiley and Sons.

Huertas, O. (2005). La participación en una cooperativa rural de ahorro y crédito: un análisis desde la cultura organizacional. Cuadernos de Desarrollo Rural, (55), 97-121. Disponible en: http://132.248.9.34/hevila/Cuadernosdedesarrollorural/2005/no55/5.pdf

Iturrioz, J., y Dopacio, C. (2009). La Responsabilidad Social en las sociedades cooperativas: una perspectiva económico financiera. Cuadernos de Estudios Empresariales, (19), 153-173. Disponible en: http://revistas.ucm.es/index.php/CESE/article/view/10104

Jácome, H. y Páez R. (2014). Desafíos para la economía social y solidaria en la región: una mirada desde la realidad del Ecuador. Serie de estudios sobre Economía popular y solidaria, Contextos de la Otra Economía. Superintendencia de Economía popular y solidaria: Quito.

Krause, L., y Konzen, O. (2002). Autonomía financiera, liquidez y capitalización interna como factores de desarrollo global en cooperativas agropecuarias de Rio Grande Del Sur-Brasil. Revista de Economía Publica, Social y Cooperativa, (43), 61-84. Disponible en: http://www.redalyc.org/pdf/174/17404305.pdf

Lara G. y Pérez F. (2015). Determinantes del isomorfismo institucional de las sociedades cooperativas de ahorro y préstamo en México. REVESCO. Revista de Estudios Cooperativos, (119), 77-106. Disponible en: http://dx.doi.org/10.5209/rev_REVE.2015.n119.49068

Ley Orgánica de Economía Popular y Solidaria. (2011). Disponible en: https://www.economiasolidaria.org/sites/default/files/Ley_de_la_economia_popular_y_solidaria_ecuador.pdf

Marcuello, C., y Saz, S. (2008). Los principios cooperativos facilitadores de la innovación: un modelo teórico. REVESCO.

Revista de Estudios Cooperativos, (94), 59-79. Disponible en: http://revistas.ucm.es/index.php/REVE/article/view/19794

Martínez, A. (2012). Sobre el principio de cooperación entre cooperativas en la actualidad. Boletín de la Asociación Internacional de Derecho Cooperativo, (46), 133-146. Disponible en: http://baidc.revistas.deusto.es/article/view/132/240

Mathuva, D. (2016). Drivers of financial and social disclosure by savings and credit cooperatives in Kenya: A managerial perspective. Journal of Cooperative Organization and Management. Vol 4, (2). 85-96. Disponible en: https://doi.org/10.1016/j.jcom.2016.08.001

Mures M., García A. y Vallejo M. (2005). Aplicación del análisis discriminante y regresión logística en el estudio de la morosidad de las entidades financieras. Comparación de resultados. Pecunia, 1. 175-199. Disponible en: https://dialnet.unirioja.es/servlet/articulo?codigo $=1281700$ 


\section{E. Coba-Molina, et al. / Contaduría y Administración 64(4) Especial Gobierno Corporativo, 2019, 1-21 http://dx.doi.org/10.22201/fca.24488410e.2020.2448}

Nieto M. y Fernández R. (2004). Responsabilidad social corporativa: la última innovación en management. Universia Business Review, Vol 1, p. 28-39. Disponible en: https://ubr.universia.net/article/view/476/responsabilidadsocial-corporativa-innovacion-management-

Paniagua, M. (2011). Los empresarios de la economía social y su valor social añadido (Del soft law comunitario a la precursora ley española de economía social). Revista de Fomento Social, (263), 359 - 399. Disponible en: https://search.proquest.com/docview/1782242895/28911A97813946B8PQ/1 ?accountid=36765

Pedrosa, C., y Hernández, J. (2011). ¿Cómo aplican las sociedades cooperativas de éxito los principios cooperativos? El caso del Grupo Hojiblanca. CIRIEC-España, Revista de Economía Pública, Social y Cooperativa, (72), 157-185. Disponible en: http://www.redalyc.org/html/174/17421345006/

Ruiz, M. y Egüez, S. (2014). Un aporte a la discusión sobre profundización financiera en

el Ecuador desde las cooperativas de ahorro y crédito. Intendencia de Estadísticas, Estudios y Normas: Quito Ecuador. Disponible

en: http://www.seps.gob.ec/documents/20181/26626/Cuaderno\%20I\%20\%20arreglado.pdf/ee4451b9-ee2b-4660870c-9d5b5dde12f0.

Sanchis, J., y Pascual, E. (2016). Banca ética y banca cooperativa. Un análisis comparativo a través del estudio de Caixa Popular y de Fiare Banca Ética. REVESCO, Revista de Estudios Cooperativos, 124. Disponible en: http://revistas.ucm.es/index.php/REVE/article/view/54921

Superintendencia de Economía Popular y Solidaria. (2017). Fichas Metodológicas de Indicadores Financieros. Versión 1.0. Disponible

en: http://www.seps.gob.ec/documents/20181/594508/NOTA+TE\%CC\%81CNICA+PARA+PUBLICAR+FICHA+ METODOLOGICAS+DE+INDICADORES.pdf/a71e5ed1-7fae-4013-a78d-425243db4cfa

Server, R., y Capó, J. (2009). La Responsabilidad Social Empresarial en un contexto de crisis. Repercusión en las Sociedades Cooperativas. CIRIEC-España, Revista de Economía Pública, Social y Cooperativa, (65), 7-31. Disponible en: http://www.ciriec-revistaeconomia.es/banco/6501_Server_y_Capo.pdf

Server, R., y Villalonga, I. (2008). Responsabilidad social y cooperativismo. El Fondo de Educación y Promoción (FEP) como indicador social en el caso del cooperativismo de crédito. Estudios de la Economía Aplicada, 26, 133 - 158. Disponible en: http://www.redalyc.org/comocitar.oa?id=30114081004

Soler, F., y Melián, A. (2012). Cooperativas de Crédito y Banca Social: Viejas y Nuevas Respuestas Éticas y Solidarias a problemas de siempre. REVESCO. Revista de Estudios Cooperativos, (109), 45-80. Disponible en: https://revistas.ucm.es/index.php/REVE/article/viewFile/40655/38978

Vargas, A. (2004). Empresas cooperativas, ventaja competitiva y tecnologías de la información". CIRIEC-España. Revista de Economía Pública, Social y Cooperativa. No 49, págs. 12-29. Disponible en: http://rabida.uhu.es/dspace/bitstream/handle/10272/7814/Empresas_cooperativas.pdf?sequence=2

Vélez, M. (2010). Una Respuesta a la Acción Social de la Rentabilidad a la Responsabilidad Social Empresarial. Revista de

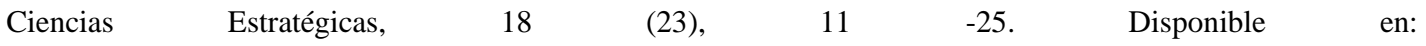
https://revistas.upb.edu.co/index.php/cienciasestrategicas/article/view/561/501

Werts, C., Linn R., Jöreskog, K. (1974). Interclass Reliability Estimates: Testing Structural Assumptions. Educational and Psychological Measurement, 34, 25-33. Disponible en: https://journals.sagepub.com/doi/10.1177/001316447403400104

Wiginton, J. (1980). A note on the comparison of logit and discriminant models of consumer credit behavior. Journal of Financial and Quantitative Analysis, 15(3), 757-770. Disponible en: https://www.jstor.org/stable/2330408?seq=1\#page_scan_tab_contents 
E. Coba-Molina, et al. / Contaduría y Administración 64(4) Especial Gobierno Corporativo, 2019, 1-21 http://dx.doi.org/10.22201/fca.24488410e.2020.2448

Zubiaurre, M., Andicoechea, L., y Saitua, A. (2016). Sociedades cooperativas de trabajo asociado versus sociedades de capital. Análisis comparado de fortaleza financiera y rentabilidad en el País Vasco. CIRIEC-España, Revista de Economía Pública, Social y Cooperativa, (86), 155-194. Disponible en: http://www.redalyc.org/pdf/174/17446072006.pdf 